\title{
Research on the Survival Analysis of Chinese ST Enterprises
}

\section{-- Analysis Based on the Life Table Method}

\author{
Haonan Tian \\ Nanjing University, Nanjing, Jiangsu, China
}

\begin{abstract}
For a long time, some companies have basically no revenue, but have not delisted from the market with poor performance, reflecting the embarrassment of the system. One of the reasons for the difficulty of enterprise delisting is the existence of ST companies in the market, which results in the scarcity of shell resources of listed companies. How to optimize the market exit mechanism has become an urgent problem to be solved. This paper selects Chinese listed companies that were processed by ST from 1998 to 2020 as the research object, and uses survival analysis to study the survival problems of ST companies, that is, the time rule of ST companies' delisting and delisting. The results show that the probability of capping incidents of listed companies after the implementation of special treatment increases first and then decreases, reaching a peak in the second year after the implementation of ST, and a substantial decline in the third year, and it can be achieved in the sixth year and beyond. Few ST companies have decapitated; the probability of delisting events of listed companies after the implementation of special treatment also increases first and then decreases, reaching a peak in the third year after the implementation of ST. In the fifth year and beyond, few ST companies have retired. city.
\end{abstract}

Keywords: Survival Analysis, ST Enterprise, Life Table Method.

\section{Introduction}

On March 1, 2016, the State Council's authorization to reform the registration system was officially implemented. On October 9, 2020, the State Council issued the "Opinions on Further Improving the Quality of Listed Companies" (hereinafter referred to as the "Opinions") and proposed to "fully implement and implement the securities issuance registration system step by step". The "Opinions" indicate the entry channel of my country's stock market Officially entered the fast lane, but at the same time, the reform of the market exit mechanism was faltering. In the early 1990s, the Shanghai Stock Exchange and the Shenzhen Stock Exchange were established successively, marking the formal formation of my country's stock market. However, many companies have experienced financial difficulties of losing money for years after going public, so the special treatment (ST) system came into being. On March 16, 1998, the China Securities Regulatory Commission issued the "Notice on the Special Handling of Stocks During the Period of Abnormal Conditions of Listed Companies", requiring the Shanghai and Shenzhen stock exchanges to implement stocks for listed companies that have suffered losses or have abnormal operating conditions for two consecutive years. Special Treatment (ST) system for transactions. On April 22, 1998, the Shanghai and Shenzhen stock exchanges announced that they would formally implement special handling of the stock transactions of listed companies with abnormal financial or other conditions, and at the same time add "ST (There are five categories of ST stocks as follows: ST, ${ }^{*} \mathrm{ST}, \mathrm{S}, \mathrm{SST}, \mathrm{S} * \mathrm{ST}$. ST_- The company has been operating at a loss for 2 consecutive years, with special treatment; *ST-The company has been operating at a loss for 3 consecutive years, with delisting warning; S-Unfinished share reform; SST_- The company has been operating at a loss for 2 consecutive years, special treatment + unfinished share reform; $\mathrm{S} * \mathrm{ST}$ — The company has been operating at a loss for 3 consecutive years, with delisting warning + unfinished share reform)" in front of their stock names.

The emergence of the ST system makes ST companies become a special group that has attracted much attention in China's capital market. On the one hand, although these companies have obtained poor results in the annual "final exams" of the exchange, because of the expectation of mergers and acquisitions and backdoor listings, the stocks of some ST companies still have high investment value. It is also the so-called high-risk and high-return; on the other hand, for scholars who study the lifespan of enterprises in the capital market, the survival of ST enterprises is a question worth exploring. Therefore, this paper uses the real data of A-share listed companies to conduct empirical research, and uses the life table method to study the time rules of the decaps and delisting of ST companies in China's listed companies.

\section{Literature Review}

The ST system is a unique system in China, and domestic scholars have conducted a lot of research on China's ST system. Chen Jing (1999) selected the financial data of 27 companies on the Shanghai and Shenzhen Stock Exchanges from 1995 to 1997 and the corresponding 27 non-ST companies as research samples to compare the financial ratio differences between ST and non-ST companies and predict The financial status of the company is used to determine whether the company will be subject to ST. Zhang Aimin and Zhu Chunshan (2001) selected 40 ST companies and 40 nonST companies corresponding to 80 companies as research samples to conduct an empirical test on the principal component prediction model of listed companies' financial failures. Zhang Zhiwang (2004) used univariate and multivariate logistic analysis to study 60 ST companies and 
120 non-ST companies from 2003 to 2004, and found that whether it was in the first year or two years before the implementation of ST, the cash flow The variables in this category all have significant incremental information content, and their efficiency in predicting financial distress is better than other financial indicators.

The limitation of these previous studies is that only financial indicators are used to predict the financial distress of ST companies, it is difficult to give in-depth explanations, and the impact of non-financial indicators is ignored. Therefore, some scholars have also included non-financial indicators into influencing factors to study ST companies on this basis. Wang Kemin and Ji Meiguang (2006) used Logistic regression model to incorporate financial and non-financial indicators into influencing factors at the same time, and found that the predictive effect of a comprehensive financial distress early-warning model was better than a single financial indicator early-warning model or a non-financial indicator early-warning model. Luo Gongli and Wu Jingchao (2007) used discriminant analysis to analyze delisted companies and non-delisted companies, and found that asset-liability ratio, account receivable turnover rate, asset turnover rate, etc. are the main factors that affect whether ST companies are delisted.

Some scholars not only pay attention to the financial status of ST companies, but also conduct empirical research in conjunction with some problems and phenomena of listed companies. Pan Yue and Dai Yi (2009) used ST companies in the Shanghai and Shenzhen stock markets from 2002 to 2007 as a sample to study the relationship between corporate political affiliation and the company's government subsidies, and found that the political affiliation of private companies is effective when the company is in financial distress. Obtaining government subsidies has a significant impact, but it does not have a significant effect on state-owned enterprises. The political connection advantage of private enterprises is affected by the degree of financial surplus in the region. The government subsidies received by private enterprises with weaker political connections have a significant effect on the improvement of the company's long-term performance. But the effect on state-owned enterprises is not significant. Cai Chun et al. (2012) studied the impact of different earnings management methods on the improvement of dying companies, namely ST companies, and the results showed that the higher the degree of invisibility of earnings management behavior, the better it is to improve their status. Shao Xinjian and Jia Zhongzheng (2014) screened out 56 backdoor ST listing samples, studied the existence and mechanism of insider trading during the backdoor listing process, and found that the ST stock price and trading volume were both before the official disclosure of control transfer information. There was a positive change, and in the last trading quarter before the suspension, the number of shareholders decreased significantly compared with the previous quarter, while the per capita shareholding ratio increased significantly, which proved that insider trading was common in the backdoor listing process. Zhao Qiwei and Zhang Nan (2015) selected Chinese industrial enterprises from 1998 to 2007 as the research sample, and applied the Weibull model and the Logistic model in the survival analysis method, which are two accelerated failure time models, to study the impact of the ownership structure of state-owned enterprises on the probability of delisting. influences.

\section{The Basic Theory of Survival Analysis}

\subsection{Survival Analysis Concept}

Survival analysis is a discipline that studies survival phenomena and response time data and its statistical laws. The following three functions are usually used to describe survival time: survival function, probability density function and hazard function.

(1) Survival function: the basic function to describe the statistical characteristics of survival time, also called survival rate. Let $\mathrm{T}$ denote survival time, $\mathrm{F}(\mathrm{t})$ is the cumulative distribution function of $\mathrm{T}$, and the survival function is defined as:

$$
S(t)=P(T>t)=1-F(t), 0<t<\infty
$$

Among them, $F(t)$ can be understood as the cumulative death rate up to time $t$.

(2) Probability density function: also known as density function. It is represented by the cumulative mortality function $F(t)$ and the death density function $f(t)$ :

$$
f(t)=\lim _{\Delta t \rightarrow 0} \frac{P(t<T \leq t+\Delta t)}{\Delta t}=F^{\prime}(t)
$$

And you can get:

$$
f(t)=F^{\prime}(t)=-S^{\prime}(t)
$$

(3) Risk function: also known as the risk function. From the density function $\mathrm{f}(\mathrm{t})$ and the survival function $\mathrm{S}(\mathrm{t})$, the risk function is expressed as:

$$
h(t)=\lim _{\Delta t \rightarrow 0} \frac{P(T \in(t, t+\Delta t) \mid T \geq t)}{\Delta t}=\frac{f(t)}{S(t)}
$$

\subsection{Life Table Method}

In order to obtain the estimation of the survival function under censored data, Kaplan and Meier (1958) gave a nonparametric estimation method of the survival function-the multiplicative positive limit method. Its advantage is that there is no requirement for the distribution of the data. It uses the principle of conditional probability and probability multiplication to Calculate survival rate, applicable to the original data (or ungrouped data) of survival time data, and can be used for small, medium or large samples.

The life table method is similar to the multiplicative limit method. The difference between the two is that when the life table calculates the survival probability, it calculates the survival probability by a certain length of time (such as day, month, year), and the calculation result is relatively rough. The life table method is usually selected when the sample size is large. Regarding the question of the timing of the delisting or delisting of ST companies to be studied in this article, the life table method is chosen, one is because of the large sample size, and the other is that what needs to be derived is the timing of the year, which does not need to be accurate. Specific date.

\section{Empirical Research on the Survival of ST Companies}

Based on the actual data of ST companies in China's Ashare market, this paper uses the life table method in the non- 
parametric method to study the time rules of ST companies' decap and delisting.

\subsection{Research Sample}

This article focuses on the companies that have been implemented "ST" among listed companies in China as the research object. Since the implementation of the ST policy in Shanghai and Shenzhen on April 27, 1998, as of December 31,2019 , a total of 970 listed companies have been subject to special treatment and wear the "ST" hat. The data comes from the CSMAR database.

Some of these "hat-wearing" companies actively responded to financial crises after the implementation of ST, adjusted their business models, turned losses into profits, completed "caps off", and returned to the stock market; some companies did not promptly respond to the implementation of ST Taking rectification measures, the operating conditions continued to deteriorate, and the market could only be delisted. Table 1 shows the delisting and delisting of ST companies over the years.

Table 1. Overview of ST in Chinese listed companies over the years

\begin{tabular}{cccc}
\multicolumn{4}{c}{ Unit: PCS } \\
\hline Years & Added ST & Uncap & Delisting \\
\hline 1998 & 30 & 0 & 0 \\
1999 & 37 & 7 & 1 \\
2000 & 31 & 20 & 0 \\
2001 & 25 & 18 & 5 \\
2002 & 52 & 19 & 8 \\
2003 & 67 & 16 & 4 \\
2004 & 45 & 28 & 11 \\
2005 & 36 & 38 & 11 \\
2006 & 64 & 19 & 13 \\
2007 & 69 & 30 & 10 \\
2008 & 29 & 41 & 2 \\
2009 & 33 & 30 & 6 \\
2010 & 39 & 23 & 4 \\
2011 & 17 & 35 & 3 \\
2012 & 27 & 35 & 3 \\
2013 & 25 & 73 & 7 \\
2014 & 38 & 45 & 3 \\
2015 & 42 & 32 & 10 \\
2016 & 61 & 42 & 2 \\
2017 & 60 & 53 & 5 \\
2018 & 54 & 41 & 6 \\
2019 & 89 & 21 & 3 \\
Total & 970 & 666 & 117 \\
\hline
\end{tabular}

It can be seen from Table 1 that from the implementation of the ST policy to the end of 2019, a total of 970 listed companies have been subject to special treatment (including those companies that have been subjected to special treatment for many times. Each time these companies are subject to ST is taken as a sample. Consider), of which 666 companies have successfully achieved "removing their hats" and 117 companies have been ordered to delist. Figure 1 and Figure 2 respectively show the delisting and delisting of ST companies from 1998 to 2019.

\subsection{Non-parametric Analysis of the Uncapped Incidents of ST Companies}

The ST system is a broad concept, including ST, *ST, S,
SST, S*ST, and PT that has withdrawn from the stage of history. Since the issue to be studied in this article does not involve the share-trading reform, it only focuses on ST and *ST enterprises.

In this article, the starting event refers to the event that the company is implemented ST, and the end event refers to the event that the ST company removes its cap or delists. Survival time refers to the time a company has experienced from the implementation of ST to the removal of caps or delisting. It mainly involves right-censored data, that is, companies that still maintain ST within the time frame specified by the research and have no decaps or delisting events.

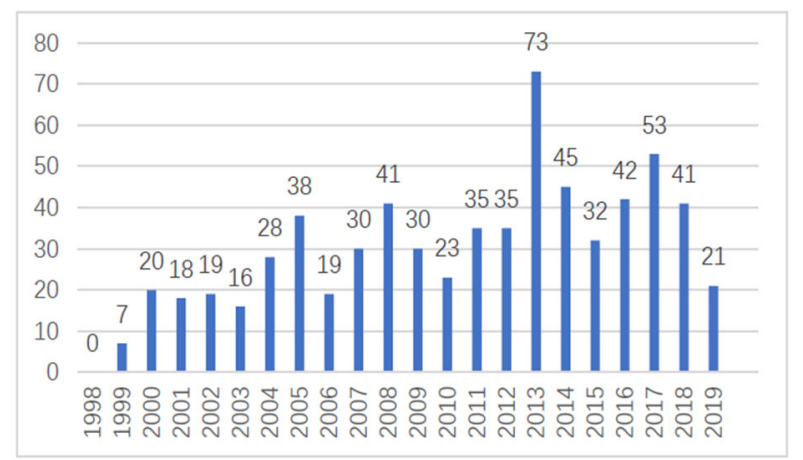

Figure 1. The removal of caps by ST companies from 1998 to 2019 (unit: units)

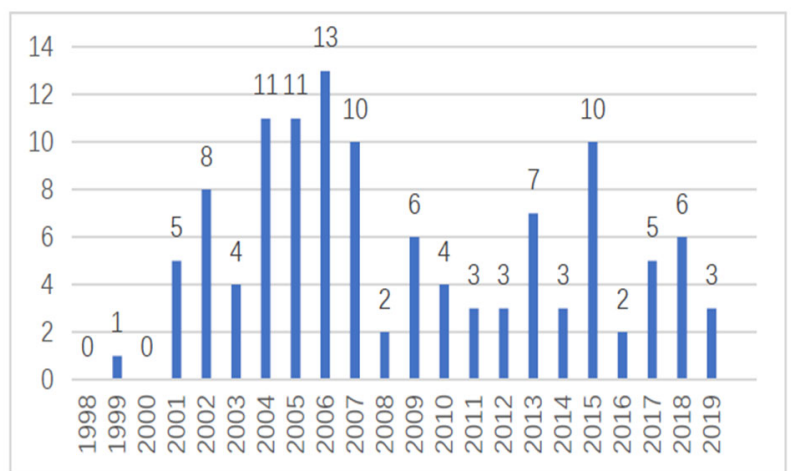

Figure 2. The delisting of ST companies from 1998 to 2019 (unit: units)

The observation period is set from 1998 to implement the special treatment policy to the end of 2019. A total of 728 ST companies have become effective samples. For all valid samples, the starting point of the survival time is the date when ST is implemented, and the end point is the occurrence of the uncap event. ST companies that have removed their caps during the observation period are uncensored samples. If they have not removed their caps and have not delisted by the end of the observation period, they are censored samples. The selected sample does not include ST companies that have delisted during the observation period.

Assuming that the survival time is one year as a unit, the entire observation period is divided into 22 time intervals, and the number of ST companies that have uncapped incidents is defined as the "number of deaths." Enter the number of censorships and deaths in each time interval based on the statistics of the CSMAR database into the SPSS software, use the life table method to analyze, and obtain the life table in Table 2: 
Table 2. The life table of the incidents of ST enterprise decaps

\begin{tabular}{|c|c|c|c|c|c|c|c|}
\hline $\begin{array}{l}\text { Survival time } \\
\text { Interval } \\
\text { (year) }\end{array}$ & $\begin{array}{c}\text { Number of } \\
\text { deaths }\end{array}$ & $\begin{array}{l}\text { Censoring } \\
\text { number }\end{array}$ & $\begin{array}{c}\text { Number of effective } \\
\text { samples at the } \\
\text { beginning of the } \\
\text { period }\end{array}$ & $\begin{array}{c}\text { Mortality } \\
\text { rate }\end{array}$ & Survival rate & $\begin{array}{c}\text { Cumulative } \\
\text { survival rate at } \\
\text { the end of the } \\
\text { period }\end{array}$ & Risk rate \\
\hline$(0,1]$ & 139 & 39 & 728 & 0.20 & 0.80 & 0.80 & 0.22 \\
\hline$(1,2]$ & 191 & 11 & 550 & 0.35 & 0.65 & 0.52 & 0.43 \\
\hline$(2,3]$ & 56 & 6 & 348 & 0.16 & 0.84 & 0.44 & 0.18 \\
\hline$(3,4]$ & 36 & 5 & 286 & 0.13 & 0.87 & 0.38 & 0.14 \\
\hline$(4,5]$ & 30 & 3 & 245 & 0.12 & 0.88 & 0.33 & 0.13 \\
\hline$(5,6]$ & 25 & 1 & 212 & 0.12 & 0.88 & 0.30 & 0.13 \\
\hline$(6,7]$ & 13 & 1 & 186 & 0.07 & 0.93 & 0.27 & 0.07 \\
\hline$(7,8]$ & 7 & 2 & 172 & 0.04 & 0.96 & 0.26 & 0.04 \\
\hline$(8,9]$ & 8 & 6 & 163 & 0.05 & 0.95 & 0.25 & 0.05 \\
\hline$(9,10]$ & 3 & 6 & 149 & 0.02 & 0.98 & 0.24 & 0.02 \\
\hline$(10,11]$ & 1 & 5 & 140 & 0.01 & 0.99 & 0.24 & 0.01 \\
\hline$(11,12]$ & 0 & 20 & 134 & 0.00 & 1.00 & 0.24 & 0.00 \\
\hline$(12,13]$ & 3 & 16 & 114 & 0.03 & 0.97 & 0.24 & 0.03 \\
\hline$(13,14]$ & 0 & 7 & 95 & 0.00 & 1.00 & 0.24 & 0.00 \\
\hline$(14,15]$ & 1 & 11 & 88 & 0.01 & 0.99 & 0.23 & 0.01 \\
\hline$(15,16]$ & 0 & 28 & 76 & 0.00 & 1.00 & 0.23 & 0.00 \\
\hline$(16,17]$ & 0 & 14 & 48 & 0.00 & 1.00 & 0.23 & 0.00 \\
\hline$(17,18]$ & 0 & 8 & 34 & 0.00 & 1.00 & 0.23 & 0.00 \\
\hline$(18,19]$ & 0 & 6 & 26 & 0.00 & 1.00 & 0.23 & 0.00 \\
\hline$(19,20]$ & 0 & 6 & 20 & 0.00 & 1.00 & 0.23 & 0.00 \\
\hline$(20,21]$ & 0 & 9 & 14 & 0.00 & 1.00 & 0.23 & 0.00 \\
\hline$(21,22]$ & 0 & 5 & 5 & 0.00 & 1.00 & 0.23 & 0.00 \\
\hline
\end{tabular}

Note: The median survival analysis time is 2.26

It is found from Table 2 that the probability of a listed company's realization of a capping event after special treatment is first increased and then decreased, reaching a peak in the second year after ST, and it can be inferred from the median survival time of 2.26 that the probability of a capping event The occurrence time is generally concentrated in the second year after ST. Starting from the second year, the probability of removing the cap decreases year by year, corresponding to the slowdown of the cumulative survival rate at the end of the period. In the sixth year and beyond, few ST companies can complete the decap.

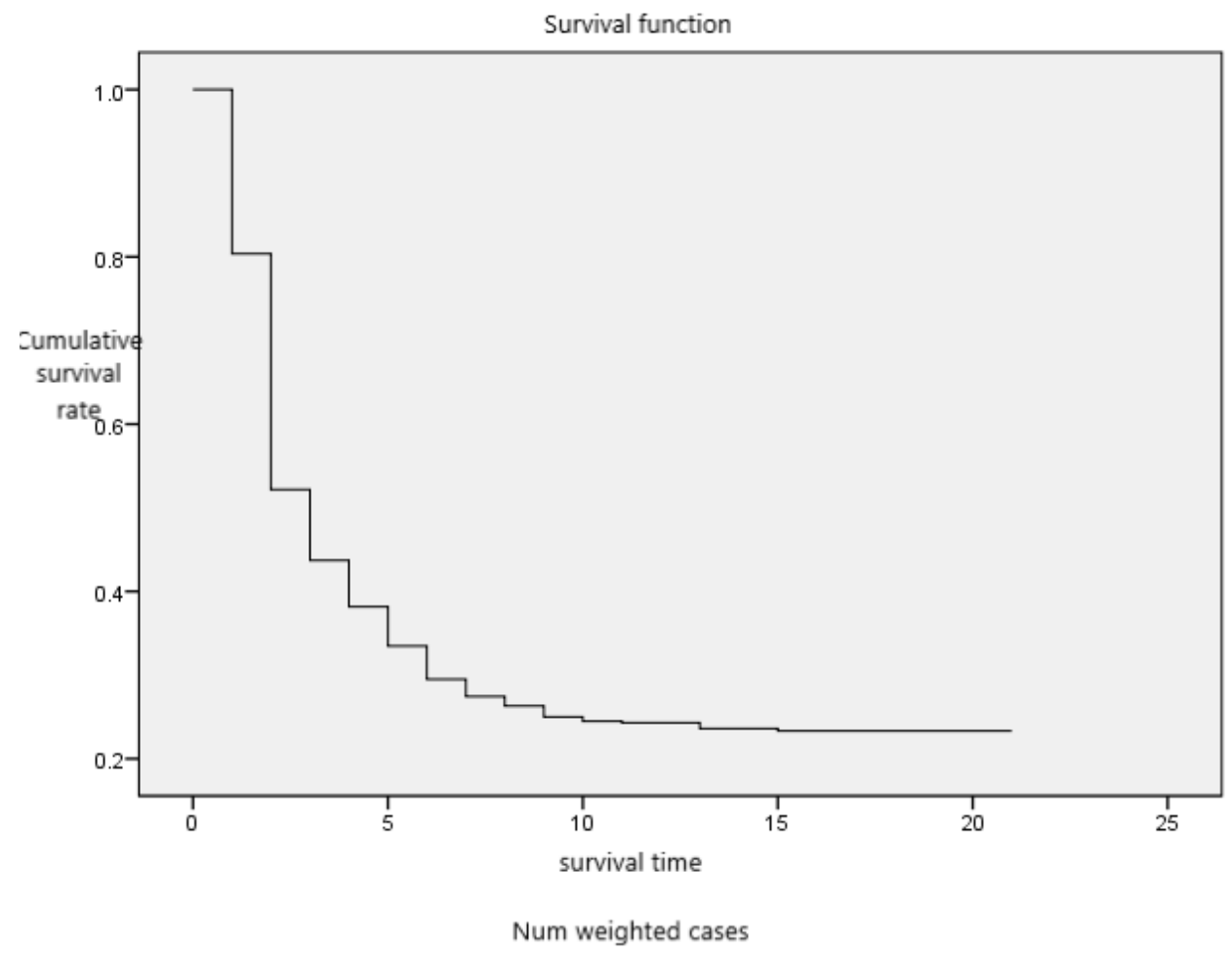

Figure 3. Survival function diagram of the ST company's decap event

According to the analysis results of the life table, the following inferences can be made: once most listed companies are subject to special treatment, they will have a sense of crisis and actively carry out rectification and improvement of business methods. This process takes about one to two years, so in the initial stage of ST There are many 
companies that have removed their caps in two years; if ST companies do not take measures to restore their loss-making operations within three years, they will face delisting warnings or direct delisting, so the number of companies that have removed their caps in the third year after ST will be greatly reduced., When listed companies have been implemented ST for more than 10 years, there is basically no possibility of removing their caps, and they can only be ordered to delist by the Securities Regulatory Commission.
The above conclusion can also be drawn from Figure 3 and Figure 4. Figure 3 is a broken line that gradually changes from steep to slow, which corresponds to the characteristic that the frequency of ST companies' uncapped incidents is generally high and then low; Figure 4 is a broken line that generally increases first and then decreases and has ups and downs in the later period. The highest point corresponds to the second year with the highest risk rate, that is, the highest probability of removing caps.

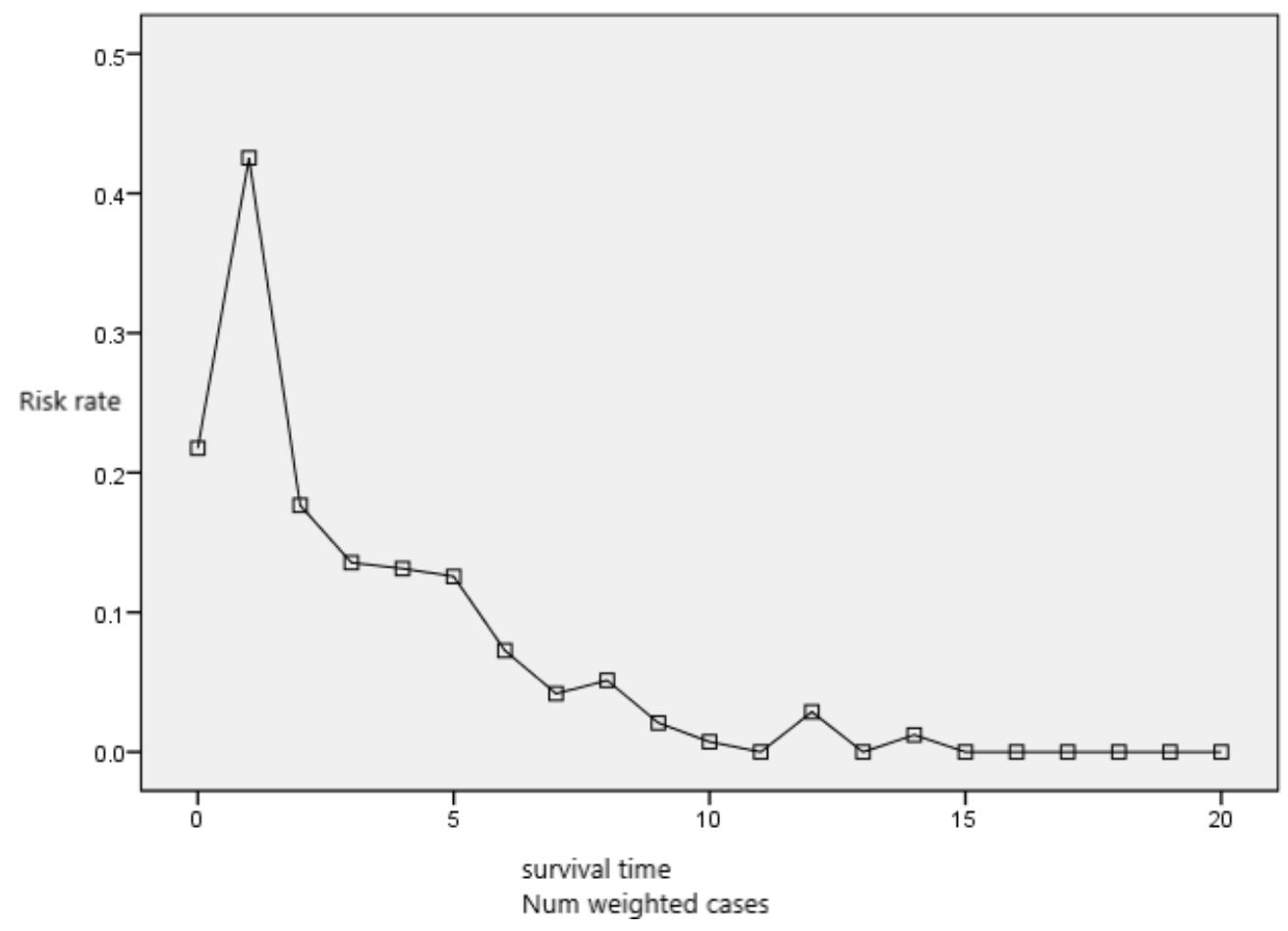

Figure 4. The risk function diagram of the ST company's decap event

\subsection{Non-parametric Analysis of ST Companies' Delisting Events}

Similar to the time rule of the research on the decap event, the observation period is still set from 1998 to the beginning of 2020, when a total of 282 ST companies have become effective samples. For all valid samples, the starting point of survival time is the date when ST is implemented, and the end point is the occurrence of delisting events. ST companies that have delisted during the observation period are uncensored samples. If they have not delisted or removed their caps by the end of the observation period, they are censored samples. The selected samples do not include ST companies that have removed their caps during the observation period.

Assuming that the survival time is 1 year as a unit, the entire observation period is divided into 22 time intervals, and the number of ST companies that have delisted events is defined as the "number of deaths." Enter the censored number and death number of each time interval based on the statistics of the CSMAR database into the SPSS software, use the life table method to analyze, and get the life table in Table 3.

It can be found from Table 3 that the probability of a delisting event after a listed company is subject to special treatment increases first and then decreases like the probability of cap removal. It is relatively high in the second and third years after ST, and reaches its peak in the third year. From the second year onwards, the probability of delisting began to show a decreasing trend. In contrast, the rate of decline in the cumulative survival rate at the end of the period is also slowing down. In the fifth year and beyond, few ST companies delisted. The result of "median survival time is $21.00 "$ in this life table has no practical significance. The reason is that there are too many censored samples in delisting events, and the cumulative survival rate is always higher than $50 \%$, which makes it impossible to calculate the median survival time.

The result obtained by analyzing the above life table is consistent with China's ST system. It is known that the China Securities Regulatory Commission stipulates that companies who lose money for two consecutive years will be delisted from the market, and listed companies who lose money for three consecutive years will be delisted, but they can apply for a one-year grace period, that is, they can delist up to two years after the implementation of ST. According to the data in the life table, if a listed company fails to make a profit in time after ST is implemented, it will be delisted one to two years after ST. Even if a grace period is applied for, if there is no operating status during the grace period Improvement, most ST companies will also complete delisting in two to three years. At the same time, it is found that a small number of companies in the life table have delisted less than one year after being ST. The reason is that although most companies' delisting is mandatory delisting, it is not ruled out that some companies require active delisting and thus delist. Other companies have completed mergers or privatizations.

The above conclusions can be more intuitively observed from the following Figures 5 and 6: Figure 5 is a broken line with a steep opening and a steep middle at the beginning and 
end, corresponding to the delisting events of ST companies concentrated in 1-4 years after being specially handled; Figure 6 is a broken line that generally increases first and then decreases with ups and downs in the later period. The highest point corresponds to the third year with the highest risk rate, that is, the highest probability of delisting.

Table 3. Life Table of Delisting Events of ST Enterprises

\begin{tabular}{|c|c|c|c|c|c|c|c|}
\hline $\begin{array}{c}\text { Survival time } \\
\text { interval } \\
\text { (years) }\end{array}$ & $\begin{array}{c}\text { Number of } \\
\text { deaths }\end{array}$ & $\begin{array}{l}\text { Censoring } \\
\text { number }\end{array}$ & $\begin{array}{c}\text { Number of effective } \\
\text { samples at the } \\
\text { beginning of the } \\
\text { period }\end{array}$ & Mortality rate & Survival rate & $\begin{array}{l}\text { Cumulative } \\
\text { survival rate at } \\
\text { the end of the } \\
\text { period }\end{array}$ & Risk rate \\
\hline$(0,1]$ & 3 & 39 & 282 & 0.01 & 0.99 & 0.99 & 0.01 \\
\hline$(1,2]$ & 20 & 11 & 240 & 0.09 & 0.91 & 0.90 & 0.09 \\
\hline$(2,3]$ & 26 & 6 & 209 & 0.13 & 0.87 & 0.79 & 0.13 \\
\hline$(3,4]$ & 5 & 5 & 177 & 0.03 & 0.97 & 0.77 & 0.03 \\
\hline$(5,6]$ & 1 & 1 & 159 & 0.01 & 0.99 & 0.74 & 0.01 \\
\hline$(6,7]$ & 2 & 1 & 157 & 0.01 & 0.99 & 0.73 & 0.01 \\
\hline$(7,8]$ & 1 & 2 & 154 & 0.01 & 0.99 & 0.73 & 0.01 \\
\hline$(8,9]$ & 1 & 6 & 151 & 0.01 & 0.99 & 0.72 & 0.01 \\
\hline$(9,10]$ & 0 & 6 & 144 & 0.00 & 1.00 & 0.72 & 0.00 \\
\hline$(10,11]$ & 1 & 5 & 138 & 0.01 & 0.99 & 0.72 & 0.01 \\
\hline$(11,12]$ & 1 & 20 & 132 & 0.01 & 0.99 & 0.71 & 0.01 \\
\hline$(13,14]$ & 0 & 7 & 95 & 0.00 & 1.00 & 0.71 & 0.00 \\
\hline$(14,15]$ & 1 & 11 & 88 & 0.01 & 0.99 & 0.70 & 0.01 \\
\hline$(15,16]$ & 0 & 28 & 76 & 0.00 & 1.00 & 0.70 & 0.00 \\
\hline$(16,17]$ & 0 & 14 & 48 & 0.00 & 1.00 & 0.70 & 0.00 \\
\hline$(17,18]$ & 0 & 8 & 34 & 0.00 & 1.00 & 0.70 & 0.00 \\
\hline$(18,19]$ & 0 & 6 & 26 & 0.00 & 1.00 & 0.70 & 0.00 \\
\hline$(19,20]$ & 0 & 6 & 20 & 0.00 & 1.00 & 0.70 & 0.00 \\
\hline$(20,21]$ & 0 & 9 & 14 & 0.00 & 1.00 & 0.70 & 0.00 \\
\hline$(21,22]$ & 0 & 5 & 5 & 0.00 & 1.00 & 0.70 & 0.00 \\
\hline
\end{tabular}

Note: The median survival analysis time is 21.00

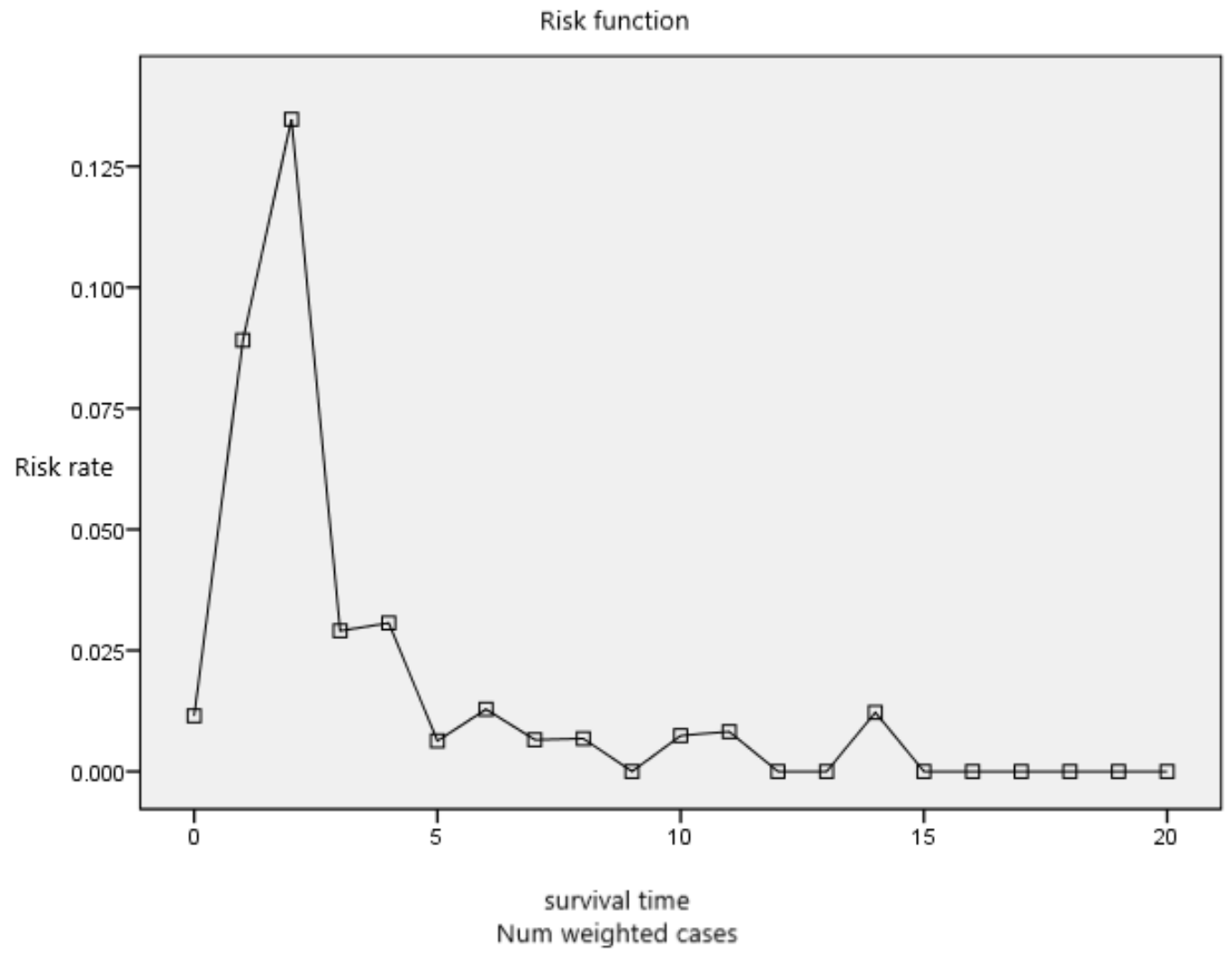

Figure 5. Survival function diagram of ST enterprise delisting event 


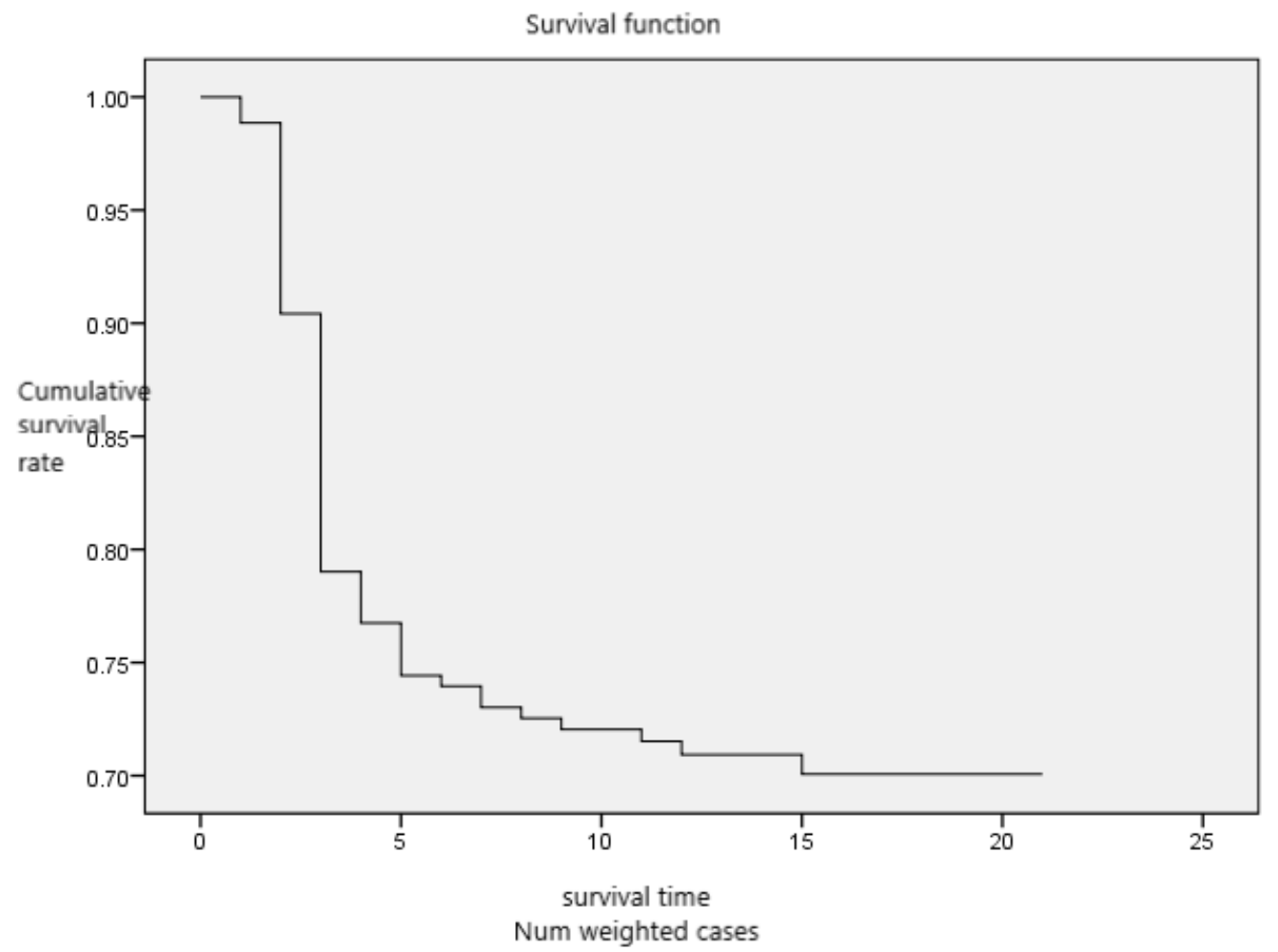

Figure 6. The risk function diagram of the delisting event of ST companies

\section{Research Conclusions}

This article takes the Chinese listed companies that were processed by ST from 1998 to 2020 as the research object. Based on the life table method, this paper explores the timing of the decap and delisting of ST companies, and the following conclusions can be drawn:

(1) After a listed company has been subject to special treatment, the probability of an event of cap removal first increases and then decreases. It peaks in the second year after $\mathrm{ST}$, and begins to drop sharply in the third year. In the sixth year and beyond, cap removal can be achieved. There are very few ST companies. This is because most listed companies will have a sense of crisis and actively rectify and reform once they are implemented. This process will take about one to two years; but if the ST company cannot recover its loss-making operation within three years, the company will basically lose its cap. Possibility.

(2) The probability of delisting of listed companies after the special treatment is implemented also increases first and then decreases, reaching a peak in the third year after ST. In the fifth year and beyond, there are very few ST companies delisting. This is because most listed companies will apply for a grace period after the ST is implemented. If there is no improvement in their operating conditions during the grace period, they will be delisted two to three years after the ST.

\section{References}

[1] Chen Jing. An Empirical Analysis of the Financial Deterioration Forecast of Listed Companies [J]. Accounting Research, 1999, 4(9): 31-38.
[2] Zhang Aimin, Zhu Chunshan, Xu Danjian. Principal component forecasting model and empirical research on the financial failure of listed companies[J]. Financial Research, 2001(03): 10-25.

[3] Zhang Zhiwang. A Quantitative Analysis of the Cost of Financial Distress of Listed Companies - Based on the Empirical Study of ST Companies from 1998 to 2002 [D]. 2004.

[4] Wang Kemin, Ji Meiguang. Research on financial early warning of loss-making companies based on financial and nonfinancial indicators - Taking company ST as an example [D]. 2006.

[5] Luo Gongli, Wu Jingchao. Research on the discrimination of ST company delisting risk based on financial indicators[J]. Journal of Qingdao University of Science and Technology (Social Science Edition), 2007(04): 45-48.

[6] Pan Yue, Dai Yiyi, Li Caixi. Political connections and government subsidies for companies in financial distress: Empirical evidence from Chinese ST companies [J]. Nankai Management Review, 2009, 12(05): 6-17.

[7] Cai Chun, Zhu Rong, He Hui, Xie Liufang. Earnings management method selection, behavioral recession and improvement of dying company status: empirical evidence from A-share special handling companies[J]. Accounting Research, 2012(09) ): 31-39+96.

[8] Shao Xinjian, Jia Zhongzheng, Zhao Yingxue, Jiang Ping, Xue Yi. Backdoor listings, insider trading and stock price changes: A study based on ST companies[J]. Financial Research, 2014(05): 126-142.

[9] Zhao Qiwei, Zhang Nan. Analysis of Ownership Structure, Subordination Relationship and State-owned Enterprise Survival[J]. Economic Review, 2015(1): 54-65. 